\title{
POLÍTICAS DE FORMAÇÃO EM EDUCAÇÃO FÍSICA E SAÚDE COLETIVA
}

\author{
POLICIES FOR TRAINING IN PHYSICAL EDUCATION AND PUBLIC HEALTH
}

\author{
Alex Branco Fraga ${ }^{1}$ \\ Yara Maria de Carvalho ${ }^{2}$ \\ Ivan Marcelo Gomes ${ }^{3}$
}

Resumo Este ensaio apresenta uma iniciativa de investigação interinstitucional que agrega três grupos de pesquisa vinculados a programas de pós-graduação em educação física: Universidade Federal do Rio Grande do Sul, Universidade de São Paulo e Universidade Federal do Espírito Santo. O tema articulador do projeto são as políticas de formação em educação física e saúde coletiva, cujo foco inicial é o Programa de Educação pelo Trabalho em Saúde. As investigações a serem empreendidas têm o propósito de acompanhar e analisar os processos de composição e articulação entre ensino, serviço e comunidade com vistas a constituir uma rede de saberes e práticas que responda aos desafios da formação em saúde comprometida com a defesa e consolidação do Sistema Único de Saúde.

Palavras-chave políticas de formação; SUS; educação física; saúde coletiva; formação profissional.
Abstract This essay presents an inter-institutional research initiative that brings together three research groups linked to graduate programs in physical education: the Federal University of Rio Grande do Sul, the University of São Paulo, and the Federal University of Espírito Santo. The main topics behind the project are the training policies for physical education and public health, which, initially, focus on the Education Program for Work in Health. The investigations to be undertaken aim to monitor and analyze the composition and coordination processes involved in teaching, in services, and in the community in pursuit of constituting a network of knowledge and practices that can meet the challenges of providing training in health committed to defending and consolidating the Unified Health System (SUS).

Keywords training policies; SUS; physical education; public health; vocational training. 


\section{Introdução}

“Políticas de formação em educação física e saúde coletiva: atividade física/práticas corporais no SUS" é o título do projeto de pesquisa interinstitucional que a Universidade Federal do Rio Grande do Sul (UFRGS), a Universidade de São Paulo (USP) e a Universidade Federal do Espírito Santo (Ufes) apresentaram em atendimento ao edital n. 24/2010 (Pró-Ensino na Saúde), lançado em maio de 2010 pela Coordenação de Aperfeiçoamento de Pessoal de Nível Superior (Capes), em parceria com a Secretaria de Gestão do Trabalho e da Educação na Saúde do Ministério da Saúde (Brasil, 2010). A intenção dessa iniciativa intersetorial é fomentar "a produção de pesquisas científicas e tecnológicas e a formação de mestres, doutores e estágio pósdoutoral na área do Ensino na Saúde" (Brasil, 2010, p. 1) em sete áreas temáticas prioritárias, 4 das quais duas nos mobilizaram de modo especial: currículo e processo ensino-aprendizagem na graduação e pós-graduação em saúde e formação e desenvolvimento docente na saúde.

Além de atender a dois temas fundamentais para as estratégias de consolidação do Sistema Único de Saúde (SUS), tal opção também nos motivou a estruturar uma rede de parcerias que pudesse articular e potencializar a discussão em torno das competências e habilidades de licenciados e bacharéis em educação física para a atuação profissional em saúde. Uma questão extremamente complexa, pois além da atuação na área ainda estar sustentada em pressupostos teóricos tradicionalmente bem distantes dos princípios do SUS, tal como acontece em boa parte dos cursos das demais áreas da saúde, a formação específica está demarcada pela disputa em torno das atribuições e limitações da atuação de licenciados fora da escola (atenção primária em saúde) e dos bacharéis em programas educacionais dentro da escola (Programa Saúde na Escola). Essas discussões têm alimentado a produção, no âmbito da graduação e pós-graduação, dos grupos de pesquisa que representam cada uma das instituições de ensino superior (IES) envolvidas neste projeto. O edital Pró-Ensino na Saúde, portanto, permitiu estreitar laços de trabalho que os respectivos grupos já mantinham, ainda que tão somente a distância.

A crítica ao modelo hospitalocêntrico de atendimento à saúde e à formação centrada em conteúdos estanques e pouco conectada aos serviços, além principalmente do predomínio da racionalidade biomédica na educação física, são os temas 'comuns' desse coletivo. Nesse sentido, foi possível articular a construção de um projeto de pesquisa interinstitucional com o objetivo de problematizar políticas de formação voltadas à capacitação e sensibilização de estudantes para atuação em educação física e saúde coletiva e analisar a implementação de práticas corporais junto ao SUS.

Apesar de compartilharmos uma série de questões referentes à formulação e condução das políticas de formação em educação física e saúde 
coletiva, o que nos conduz neste projeto é também o que nos diferencia: trajetórias de formação, de pesquisa e de filiação teórica. É a pluralidade de ideias e experiências resultante do encontro entre grupos que poderá, de alguma forma, contribuir para a produção de novos sentidos e significados às 'políticas de formação'. E, para entender essa equação singular, é preciso enveredar pelos caminhos que cada grupo já percorreu até aqui.

\section{Um coletivo no singular: a trajetória de cada grupo de pesquisa}

A tarefa de pensar as políticas de formação em educação física na perspectiva da saúde coletiva é bastante complexa, pois não são muitos os pesquisadores envolvidos em linhas de pesquisa com essa temática em programas de pós-graduação em educação física no Brasil. Mais recorrentes são os grupos que se dedicam ao tema 'formação docente' com trabalhos diretamente relacionados à prática pedagógica nas redes públicas de ensino (Molina Neto e Molina, 2003; Figueiredo, 2005; Bracht et al., 2007; Terra e Souza Júnior, 2010). Entretanto, 'formação em saúde', nessa área específica, ainda é um tema pouco explorado e carece de parcerias e redes de colaboração em pesquisa mais efetivas. Apesar dos diferentes 'tempos de estrada' de cada grupo, responder a essa demanda é um dos compromissos desse coletivo.

\section{Educação Física \& Saúde Coletiva \& Filosofia - USP}

O grupo de pesquisa Educação Física \& Saúde Coletiva \& Filosofia está vinculado ao Laboratório de Pedagogia do Movimento e ao Programa de Pós-Graduação em Pedagogia do Movimento da Escola de Educação Física e Esporte da USP. Dos três grupos envolvidos neste projeto interinstitucional, é o grupo que há mais tempo vem discutindo a respeito do campo denominado 'saúde coletiva' na educação física. Foi cadastrado no Conselho Nacional de Desenvolvimento Científico e Tecnológico (CNPq) em 1999, inicialmente com o propósito de agregar pesquisadores e estudantes com interesse em problematizar a relação 'atividade física e saúde', desnaturalizála e, ao mesmo tempo, propor outros modos de intervir com os conteúdos da área específica, a partir das ciências humanas e sociais e no diálogo e na articulação com o campo acadêmico saúde coletiva. E, mais recentemente, acrescentamos ao próprio nome do grupo a filosofia, haja vista nossas pesquisas e formação exigirem uma aproximação mais sistemática com os filósofos do século XVII e os considerados pós-modernos. 5

No que se refere ao foco temático, é no início da década de 1990 que Yara Maria de Carvalho, coordenadora do grupo, apresenta os primeiros 
estudos chamando a atenção para a relação 'atividade física e saúde' e também para a formação em educação física sob o enfoque da saúde coletiva. Com o aporte teórico da história, filosofia e sociologia, Carvalho busca nos problemas estruturais da sociedade - indústria cultural, política neoliberal, indústria da beleza e farmacêutica, sociedade de consumo e tecnologias elementos para explicar a ênfase na ideia de que a atividade física, por si só, produz saúde e, ao mesmo tempo, desenvolver um contraponto a esse tipo de apelo (Carvalho, 2004).

Se o enfoque inicial era sobre o processo de institucionalização da atividade física, em seguida enfatizou problemas relativos à 'comunidade'. $A$ arte de fazer a vida melhor: narrativas dos que fazem a festa de Achiropita é o título da tese de doutorado defendida no Departamento de Medicina Preventiva da Universidade Estadual de Campinas (Unicamp) - hoje Departamento de Saúde Coletiva -, em 1999 (Carvalho, 1999). O objetivo foi investigar os caminhos, os modos de viver daqueles que faziam a festa, combinando narrativas e observações realizadas em seus bastidores. Festa do povo, de imigrantes, italianos, negros e nordestinos, onde trabalho e lazer não estão dissociados e podem ser compreendidos como tempos e espaços de produção de saúde.

Especificamente no âmbito da atenção primária, Yara Maria de Carvalho iniciou sua experiência no Centro Saúde Escola Samuel B. Pessoa, no Butantã, em São Paulo, em 1999. Reuniu estudantes da graduação que tinham interesse em dança, ginásticas e orientação postural e propôs uma intervenção. Dois anos depois, estudantes de pós-graduação iniciaram investigações com o objetivo de rever teorias e conceitos correntes na educação física diretamente relacionados à atividade física, à saúde, à doença, ao cuidado, à atenção primária e às práticas de saúde. Pesquisas de natureza qualitativa que buscam contribuir na implementação de propostas de educação física efetivamente sintonizadas com as necessidades de saúde da comunidade e em diálogo com diferentes áreas do conhecimento, a fim de ressignificar as práticas de saúde e o cuidado (Freitas, 2007; Marcondes, 2007).

Dessa iniciativa local, resolveu ampliar o território de investigação. Em parceria com pesquisadores do Departamento de Prática de Saúde Pública da Faculdade de Saúde Pública da USP, iniciaram um processo de avaliação a respeito do que existia de práticas corporais nas 14 unidades básicas de saúde (UBS) do distrito de Butantã. Verificaram as condições dos bairros e das UBS; identificaram o perfil da comunidade usuária do SUS; entrevistaram gerentes e funcionários, especialmente aqueles que tinham alguma ligação com as iniciativas de práticas; mapearam os programas específicos, com o intuito de caracterizar como e quais práticas estavam sendo promovidas; identificaram os problemas, as necessidades e os interesses dos 
profissionais do serviço vinculados aos programas; e delinearam as particularidades, os desafios e as expectativas das instituições com relação às práticas corporais. Das 14 unidades avaliadas, apenas quatro não tinham programas. Entretanto, dos dados obtidos, foi possível evidenciar a desarticulação entre os responsáveis pelas práticas, a gerência e os profissionais da saúde, assim como identificar controvérsias relativas ao impacto e à relevância das iniciativas e, consequentemente, do envolvimento dos usuários (Warschauer et al., 2007).

O desafio seguinte, viabilizado por uma parceria entre a Fundação de Amparo à Pesquisa do Estado de São Paulo (Fapesp), o CNPq e o Ministério da Saúde, via edital especial "Políticas Públicas e SUS (PPSUS)", foi a aproximação com os usuários - participantes e não participantes das iniciativas com práticas corporais. Foram 1.096 questionários aplicados com o intuito de identificar o perfil da comunidade e quase 200 entrevistas, algumas com mais de uma hora de duração, a fim de ampliar e qualificar as condições de interpretação e compreensão a respeito dos cuidados com o corpo no contexto do SUS. Ao mesmo tempo, buscava-se visualizar se o diálogo entre comunidade e serviço, por meio das práticas corporais, acontecia e de que modo, ou se havia imprecisões e descompassos entre os programas oferecidos e as necessidades, os interesses e os desejos dos usuários (Carvalho, 2010).

Com financiamento do Ministério da Saúde, por meio da Secretaria de Vigilância à Saúde e em parceria com um grupo de pesquisa da Universidade Federal de Pelotas, entre 2008 e 2009, avaliaram dois programas de atividade física: o Academia da Cidade do Recife, em Pernambuco, e o CuritibAtiva, no Paraná. O desafio era agregar pesquisa quantitativa e qualitativa a fim de analisarem com mais propriedade o impacto e a relevância de iniciativas envolvendo atividade física junto à população.

“Caminhos da Integralidade: levantamento e análise de tecnologias de cuidado integral à saúde em serviços de atenção primária em região metropolitana" foi outro projeto com o qual o grupo de pesquisa colaborou, vinculado à Faculdade de Medicina e ao Centro Saúde Escola Samuel B. Pessoa da USP. Pesquisadores, docentes e estudantes de graduação e pósgraduação investigaram o modo como o princípio da integralidade tem sido operado nas UBS no distrito de Butantã. Foi um estudo sobre tecnologias de atenção primária à saúde, de caráter qualitativo, com metodologias combinadas (entrevistas, observações e grupos focais). Dos resultados, cabe destacar os subsídios para a construção de indicadores de integralidade para planejamento e avaliação de ações de atenção primária, mapeamento e otimização de inovações tecnológicas e fortalecimento de redes intra e interserviços (Ayres et.al., 2012). 


\section{Políticas de Formação em Educação Física e Saúde (Polifes) - UFRGS}

Políticas de Formação em Educação Física e Saúde (Polifes) é um grupo de estudos e de pesquisas vinculado à Escola de Educação Física (Esef) da UFRGS e ao Programa de Pós-Graduação em Ciências do Movimento Humano (PPGCMH). Criado em novembro de 2009, dedica-se a investigar questões referentes às políticas de formação no campo da educação física em interface com as áreas da educação e da saúde coletiva. Acolhe projetos que examinam, dentro de uma perspectiva preferentemente biopolítica, a implicação dos preceitos da vida ativa e da vida saudável na cultura corporal de movimento, na educação dos corpos e na regulação da saúde. Currículo, docência, práticas corporais em serviços de saúde, programas de promoção da atividade física e artefatos culturais midiáticos compõem o terreno investigativo sobre o qual as pesquisas se desenvolvem.

Apesar de o grupo ter se constituído formalmente em 2009, é possível afirmar que os projetos de pesquisa atualmente desenvolvidos pelo Polifes dentro da temática formação em educação física e saúde estão de algum modo relacionados ao marco teórico desenvolvido por Alex Branco Fraga, coordenador do grupo, na tese Exercício da informação: governo dos corpos no mercado da vida ativa, defendida em 2005 no Programa de Pós-Graduação em Educação da UFRGS. 6 Neste trabalho, Fraga analisa de que modo a disseminação de informações sobre os benefícios da vida ativa e os riscos do sedentarismo foram se tornando centrais na promoção da saúde e na educação física contemporânea. A partir do programa de promoção de atividade física Agita São Paulo, o autor procura movimentar a estrutura aparentemente estável do discurso da vida ativa e desatar alguns nós que amarram significados positivos e negativos em torno da equação 'estilo de vida ativo versus sedentarismo'. Por meio do conceito de biopolítica de Michel Foucault e das formulações pontuais de Gilles Deleuze acerca da passagem das sociedades disciplinares às sociedades de controle, articuladas à noção de risco em saúde como uma forma de governo à distância, o autor mostra como o exercício da informação se tornou um modo privilegiado de governar os corpos no agitado mercado da vida ativa.

A primeira grande pesquisa em grupo produzida a partir dos achados do trabalho de Fraga foi registrada em 2006 sob o título "Estilo de vida ativo versus sedentarismo: efeitos de um programa de promoção de atividade física e saúde na cultura corporal urbana", uma experiência desenvolvida no Núcleo UFRGS da Rede Cedes. O objetivo era investigar em uma comunidade particular o grau de penetração da massiva circulação de mensagens que informavam sobre a correlação positiva entre os trinta minutos de atividade física moderada e saúde e apontar possíveis efeitos do processo 
de disseminação dessas recomendações na cultura corporal urbana local. A publicação, em 2007, do livro Educação Física \& Saúde Coletiva: políticas de formação e perspectivas de intervenção (Fraga e Wachs, 2007) foi um dos produtos mais significativos dessa pesquisa.

Em 2007, o Núcleo UFRGS da Rede Cedes investe no projeto “Políticas de promoção da saúde na gestão do lazer em Porto Alegre", também financiado pelo Ministério do Esporte. O objetivo geral era verificar o impacto social das políticas de promoção da saúde na gestão do lazer, no processo de significação da atividade física como elemento de promoção da saúde, nas sociabilidades aí decorrentes e no estilo de vida da população urbana frequentadora de parques públicos. Coube aos atuais membros do Polifes analisar os significados de 'sedentarismo' e 'sedentário' para praticantes de caminhada vinculados a um programa público de lazer e saúde de Porto Alegre em relação ao processo de medicalização das práticas corporais inscrito nas recomendações referentes à atividade física e saúde. Deste projeto resultou o livro Políticas de lazer e saúde em espaços urbanos, organizado por Fraga et al., publicado pela editora Gênese em 2009.

Em 2008, a primeira dissertação de mestrado produzida pelo grupo é defendida no PPGCMH: “Educação Física e Saúde Mental: uma prática de cuidado emergente em Centros de Atenção Psicossocial (Caps)", de autoria de Felipe Wachs. Esse trabalho tratou da relação entre educação física e saúde mental e teve como principal objetivo "discutir os sentidos que circulam em Centros de Atenção Psicossocial (Caps) sobre a presença de professores de educação física e sobre as práticas desenvolvidas por eles no interior desse serviço" (Wachs, 2008 p. 7). Desde então, já foram defendidas oito dissertações, duas ainda estão em andamento e três teses de doutorado estão sendo desenvolvidas dentro da temática educação física e saúde coletiva.

Em 2010, o Núcleo UFRGS da Rede Cedes, mais uma vez contando com o financiamento do Ministério do Esporte, começou a desenvolver o projeto “Escola de Educação Física da Universidade Federal do Rio Grande do Sul (1940-2010): mapeando cenários da formação profissional e da produção do conhecimento em políticas públicas de esporte e lazer". O objetivo central era analisar o papel da Esef/UFRGS no desenvolvimento da educação física, do esporte e do lazer nos âmbitos local, regional e nacional. Coube ao Polifes investigar a história curricular dos cursos de educação física oferecidos por essa instituição de ensino superior nos seus 70 anos de existência. Parte dos achados dessa investigação foi publicada em artigo na revista Movimento, com o título "Alterações curriculares de uma escola septuagenária: um estudo sobre as grades dos cursos de formação superior em Educação Física da Esef/UFRGS" (Fraga et al., 2010). 


\section{Laboratório de Estudo em Educação Física (Lesef) - Ufes}

O Laboratório de Estudos em Educação Física (Lesef) pertence ao Centro de Educação Física e Desportos (CEFD) da Ufes. Quando foi fundado, no ano de 1996, contava com professores vinculados ao chamado Movimento Renovador da Educação Física,7 que buscavam, a partir de diferentes temáticas, contribuir para a construção da teorização pedagógica da área desenvolvendo estudos que permitissem analisar a construção histórica das teorias e práticas pedagógicas da educação física e seus desdobramentos contemporâneos, principalmente no campo escolar.

A temática da saúde aparecia nesse momento vinculada a tais preocupações, mas, em função de uma reestruturação interna, que gerou a saída de alguns e a posterior formação de outros grupos no CEFD/Ufes, as pesquisas desenvolvidas não chegaram a problematizar a questão da saúde como tema central. Dessa forma, a saúde era um elemento que atravessava as pesquisas, embora não fosse o motor das teorizações construídas.

Um exemplo que ilustra esse processo pode ser a ampla pesquisa realizada pelo Lesef intitulada "A educação física como componente curricular e o discurso legitimador". O objetivo era compreender os discursos que legitimaram a educação física como componente curricular das escolas no Brasil por meio das análises dos discursos presentes em periódicos datados entre as décadas de 1930 e 1980 . A investigação mostrou, dentre outras questões, a importância de se avançar na reflexão sobre a relação da área com o campo da saúde e da própria teorização sobre as diferentes utilizações da noção de saúde na educação física. No entanto, essas questões ficaram nos termos desse reconhecimento e da aposta, não se efetivando nos estudos do Lesef.

Mais recentemente, com a entrada de novos pesquisadores, bem como o diálogo estabelecido por membros do Lesef com outros grupos de pesquisa, foi possível que a temática da saúde emergisse como uma questão fundamental e se transformasse em eixo central dos estudos no laboratório. A criação e posterior entrada da primeira turma do mestrado em educação física do CEFD/Ufes potencializou essa opção que agora se materializa na participação de membros do Lesef em duas linhas de pesquisa do PPGEF/CEFD/Ufes que dão atenção à temática da saúde: “Educação física, corpo e movimento humano" e "Educação física, sociedade e saúde".

Atualmente, é possível identificar três frentes de pesquisa relacionadas à temática da saúde no grupo: os discursos contemporâneos sobre a saúde em artefatos culturais; a teorização sobre vida e saúde em diferentes práticas corporais e em espaços destinados para tais fins; e a relação entre saúde e adoecimento vivida pelos professores de educação física. ${ }^{8}$ Essas pesquisas se materializam em uma série de iniciativas vinculadas a orientações de 
trabalhos na graduação e na pós-graduação e na articulação do Lesef com outros grupos de pesquisa.

Exemplos disso são os trabalhos que se desdobram da tese de doutorado de um dos membros (Gomes, 2008), que priorizam a teorização e análise da noção de saúde em produções acadêmicas e midiáticas que tematizavam a elaboração e a difusão de estilos de vida saudáveis. A partir do diálogo com as ciências humanas, esse trabalho analisou como tais propostas para o cultivo da vida saudável se enquadravam em uma cientificização do cotidiano. Esses discursos de verdade sobre a vida potencializam ansiedades contemporâneas ao realizarem insistentes alertas quanto à necessidade de autovigilância baseados nos conhecimentos e conselhos oferecidos para esse enfrentamento individual.

Os apontamentos finais desse trabalho indicavam a necessidade de estudos que o complementassem, além das propostas e dos modelos que foram analisados. Alguns trabalhos desenvolvidos atualmente no Lesef buscam suprir essas lacunas ao discutirem a recepção desses discursos pelos usuários de serviços de saúde, como, por exemplo, a dissertação de um dos membros do Lesef (Beccalli, 2012) que procura refletir sobre a apropriação pelos usuários desses discursos especializados oferecidos e vivenciados no Serviço de Orientação ao Exercício da Prefeitura Municipal de Vitória.

Assim, a partir das ramificações dessa tese, o Lesef retoma o diálogo com a saúde, dando maior visibilidade e importância para essa questão nos projetos desenvolvidos por esse grupo de pesquisa (Quadro 1).

Resumo do referencial teórico-metodológico dos grupos de pesquisa

\begin{tabular}{|c|c|c|c|c|c|}
\hline & Conceitos & $\begin{array}{l}\text { Perspectivas } \\
\text { metodológicas }\end{array}$ & Áreas & Corpus & Autores \\
\hline & Biopolítica & Narrativas & Saúde coletiva & Corpo & Bauer, M. \\
\hline & Práticas corporais & Etnografia & Educação física & PET-saúde & Campos, G.W.S. \\
\hline & Formação em saúde & Cartografia & Filosofia & Unidades básicas de saúde & Deleuze, G. \\
\hline \multirow[t]{4}{*}{ USP } & Atenção primária em saúde & Pesquisa bibliográfica & Educação & Programas de atividade física & Foucault, M \\
\hline & Cuidado & Análise documental & & Formação em saúde & Kastrup, V. \\
\hline & Comunidade & & & & Passos, E. \\
\hline & Saúde ampliada & & & & Spinoza, B. \\
\hline
\end{tabular}


Continuação - Quadro 1

Resumo do referencial teórico-metodológico dos grupos de pesquisa

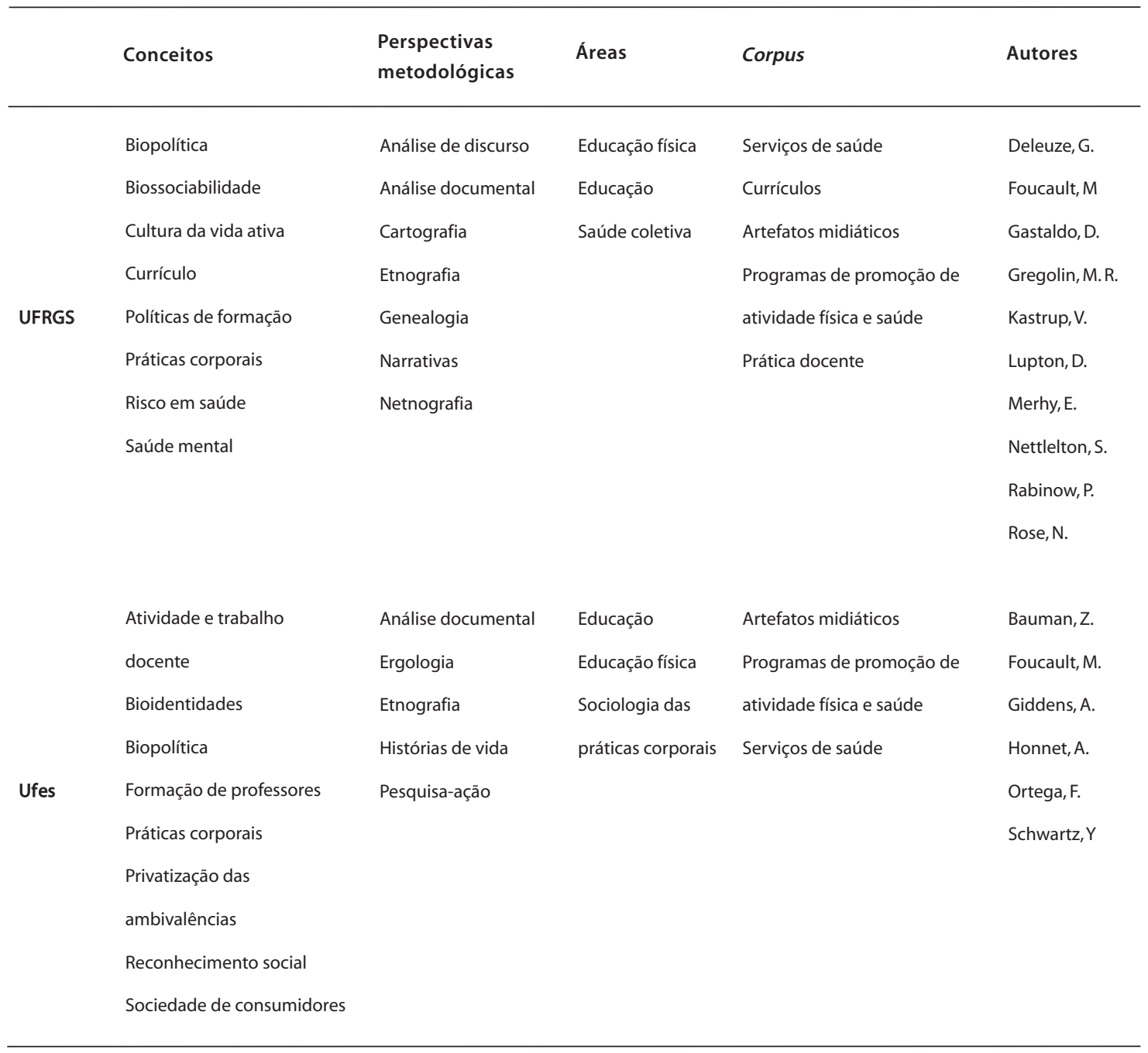

Fonte: Os autores.

\section{Políticas de formação: singularidades de um projeto coletivo}

A criação e a regulamentação do SUS, no final da década de 1980, mais precisamente em 1988 e início de 1990, mudaram radicalmente a estrutura e a organização dos serviços de saúde no Brasil. A institucionalização dos princípios da universalidade, da integralidade e da equidade, bem como das diretrizes operacionais baseadas na descentralização, regionalização, hierarquização e na participação popular (controle social), reclama dos profissionais da saúde uma forma de atuar distinta, "calcada na ação intersetorial e no 
empoderamento (empowerment) da população" (Haddad et al., 2010, p. 386). Contudo, a consolidação desses princípios passa, necessariamente, pela mudança no processo de formação dos profissionais, pois ainda vigora, no ambiente formativo da maioria dos cursos de graduação e pós-graduação, lato e strictu senso, uma visão predominantemente biomédica do processo saúde-doença e uma forma de organização curricular centrada na transmissão de conhecimento, hierarquizado e verticalizado.

Desde a criação da Secretaria de Gestão do Trabalho e da Educação na Saúde (SGTES), em 2003, o Ministério da Saúde vem investindo fortemente na formação dos profissionais que atuam no SUS e na aproximação entre as instituições formadoras e os serviços de saúde. Entre as ações desenvolvidas, cabe destacar a do Programa Nacional de Reorientação da Formação Profissional em Saúde - Pró-Saúde (Brasil, 2009). Lançado pela portaria interministerial MS/MEC n. 2.101, de 3 de novembro de 2005, foi baseado no Programa de Incentivos às Mudanças Curriculares para as Escolas Médicas (Promed), ${ }^{9}$ que tinha por objetivo fomentar a reorientação da formação de três cursos de graduação: enfermagem, medicina e odontologia.

Em 2007, a portaria interministerial MS/MEC n. 3.019 instituiu o PróSaúde II, que abarcou os outros 11 cursos de graduação da área da saúde que não haviam sido contemplados na primeira fase, mantendo os três cursos fomentados pelo programa anterior. A inclusão dos cursos, além de estar alicerçada no mesmo princípio que sustenta o trabalho multiprofissional nos serviços, também potencializa as estratégias de reorientação da formação nas universidades, tendo em vista abrigarem cursos bem mais antigos do que o próprio SUS e, não raras vezes, resistirem às mudanças necessárias. Entre os 354 cursos contemplados no edital, 19 eram da educação física, demonstrando o potencial de uma área com inserção ainda incipiente na rede de serviços públicos de saúde (Brasil, 2009).

Para entrelaçar de modo mais firme a relação entre ensino e serviço e comunidade nos cursos de formação em saúde, o Programa de Educação pelo Trabalho para a Saúde (PET-Saúde) foi instituído por meio da portaria interministerial MS/MEC n. 1.802/2008. Trata-se de uma estratégia vinculada ao Pró-Saúde, destinada a fomentar grupos de aprendizagem tutorial na Estratégia Saúde da Família (Haddad et al., 2009). Cada grupo PET-Saúde/Saúde da Família é formado por um tutor acadêmico, 30 estudantes - sendo 12 estudantes monitores, que efetivamente recebem bolsas - e seis preceptores.

Na edição de 2011, foram selecionados 484 grupos PET-Saúde/Saúde da Família, o que representa 9.196 bolsas ao mês além da participação de 8.712 estudantes não bolsistas, totalizando 17.908 participantes ao mês. Em termos de projetos, são 111 de pesquisa, de 84 IES e 96 secretarias municipais de Saúde. As parcerias estabelecidas na formulação, na implementação, no monitoramento e na avaliação do PET-Saúde envolvem a SGTES/MS, 
a Secretaria de Atenção à Saúde (SAS/MS), a Secretaria de Vigilância em Saúde (SVS/MS), o Fundo Nacional de Saúde (FNS/SE/MS), o Datasus/SE/MS, o Conselho Nacional de Secretários de Saúde (Conass), o Conselho Nacional de Secretários Municipais de Saúde (Conasems), a Secretaria Nacional de Políticas sobre Drogas (Senad/GSI/PR) e a Secretaria de Educação Superior (Sesu/MEC). Há dois outros formatos de PET-Saúde que merecem destaque: o Saúde Mental/Crack e o da Vigilância em Saúde (Brasil, 2011).

É significativo perceber que, nessas diferentes estratégias voltadas à formação para as diferentes áreas da saúde, a educação física tem sido reiteradamente contemplada, ainda que o movimento de organização interna, da área, seja quase imperceptível. E essas ações intersetoriais já começam a produzir reações e efeitos na formação dos estudantes, especialmente dos que estão envolvidos com o PET-Saúde. Já se percebe um tênue movimento de inserção de disciplinas e estágios que tratam do SUS em alguns currículos da graduação (Pasquim, 2010). Contudo, as fortes tradições técnico-esportiva e médico-científica têm gerado resistências consideráveis ao processo de reformulação de currículos e de práticas docentes em larga escala na formação superior nessa área.

A educação física emergiu com força no interior do processo de higienização e mecanização dos corpos do século XIX e se escolarizou por meio dos métodos ginásticos europeus no início do século XX. Mas só foi reconhecida formalmente, no Brasil, como uma das categorias profissionais da saúde de nível superior em 1997, por meio da resolução n. 218 do Conselho Nacional da Saúde (CNS). 10 Deste reconhecimento pelo CNS, a formação profissional seguiu majoritariamente centrada na epidemiologia do risco, no modelo clínico/prescritivo e na visão biomédica do processo saúde-doença, portanto, ainda distante dos princípios constantes dessa resolução.

Os cursos de formação profissional em educação física no Brasil remontam às "primeiras décadas do século XX em cursos de curta duração voltados prioritariamente para a formação dos militares" (Benites, Souza Neto e Hunger, 2008, p. 346). Até meados da década de 1960, a formação de instrutores de ginástica com ênfase em saberes técnico-biológicos preponderava, mesmo nas escolas civis (Azevedo e Malina, 2004). A partir da década de 1960, o movimento de 'esportivização' da educação física ganha fôlego, insuflado pelo nacionalismo do regime militar, e sustenta a conformação de um perfil profissional híbrido: professor de educação física/técnico desportivo (Fraga et al., 2010).

O cenário se altera com a homologação da resolução n. 3/1987, pelo Conselho Federal de Educação, que institucionaliza cursos de bacharelado em educação física no Brasil, instaurando outro tipo de fragmentação no processo de formação, ainda que restrito a poucas universidades. Com a promulgação da lei n. 9696/1998, que cria o Conselho Federal e os Conselhos 
Regionais de Educação Física, e a homologação da resolução n. 7/2004, pelo Conselho Nacional de Educação (CNE), que instituiu as Diretrizes Curriculares para os cursos de graduação em educação física, os debates se tornaram mais intensos em torno da divisão da formação profissional e do campo de atuação de licenciados e bacharéis (Fraga et al., 2010).

Mesmo sem mencionar o termo bacharelado, a resolução n. 7/2004 (CNE) (Brasil, 2004) acaba reiterando na figura do 'graduado' as atribuições previstas para o bacharel na resolução n. 3/1987 (CFE) (Brasil, 1987). Faz menção, breve, ao licenciado, remetendo a maior parte das especificações às resoluções n. 1 e n. 2/2002 do CNE (Brasil 2002a; 2002b) que instituíram as Diretrizes Curriculares Nacionais para a Formação de Professores da Educação Básica. Porém, percebe-se que um dos objetivos principais daquela resolução é estabelecer as competências do profissional que atuará fora da escola (Fraga et al., 2010). É curioso observar que o SUS não é sequer mencionado nas referidas diretrizes, reafirmando a distância entre as políticas de formação em educação física e as do campo da saúde.

É possível supor que o silêncio sobre o SUS nas diretrizes da educação física esteja relacionado à baixa visibilidade dos profissionais dessa área nas ações propostas pela gestão dos serviços, como também (e talvez este seja o elemento mais significativo) pela falta de compreensão das demandas do SUS para a área específica. A inserção formal dos profissionais da educação física em ações programáticas, como a Estratégia Saúde da Família (ESF), o Núcleo de Apoio à Saúde da Família (Nasf) ou ainda os Caps, indica, tanto para o campo da saúde quanto para a área da Educação Física, a potencialidade deste profissional na articulação de práticas de cuidado de caráter multiprofissional, inspiradas no princípio da integralidade da atenção.

Contudo, além de saber como responder às necessidades sociais de saúde (Freitas, Brasil e Silva, 2006), é também preciso entender as 'regras' do jogo de relações conceituais, conflitantes, contidas no par 'atividade física/práticas corporais'. Embora ambos apareçam quase sempre juntos em grande parte dos textos das políticas de saúde vigentes no país, eles não são sinônimos. Estão lado a lado justamente porque são noções distintas (Carvalho, 2006).

O termo 'atividade física' tem uma definição mais precisa: qualquer movimento produzido pelos músculos esqueléticos que resulte em gasto de energia física acima do basal (Caspersen, Powell e Christenson, 1985). Uma definição obtida em conferência de consenso no interior da comunidade científica da área, mas que reduz o movimento humano a um indicador fisiológico. O termo 'práticas corporais' é polissêmico, não se enquadra em uma taxionomia redutora do movimento, pois nele se inscreve a cultura corporal de movimento. Diz respeito ao ser humano em movimento, à sua gestualidade, aos seus modos de se expressar corporalmente. São componentes da cultura corporal, conjunto de expressões e manifestações corporais 
construídas e codificadas historicamente por diferentes sociedades (Carvalho, 2006), tais como a ginástica, a dança, o jogo, as lutas, o esporte, as práticas junto à natureza, as atividades aquáticas etc.

Em artigo de revisão sobre o uso do termo na literatura acadêmica brasileira, Lazzarotti Filho et al. (2010, p. 25) apontam que especificamente na educação física “o termo 'práticas corporais' vem sendo valorizado pelos pesquisadores que estabelecem relação com as ciências humanas e sociais, pois aqueles que dialogam com as ciências biológicas e exatas operam com o conceito de atividade física".

As práticas corporais podem se tornar, no SUS, um espaço interessante para compor com o cuidado e a atenção em saúde. Dadas as suas características, elas ampliam as possibilidades de encontrar, escutar, observar e mobilizar as pessoas para que, no processo de cuidar do corpo, elas efetivamente construam relações de vínculo, de corresponsabilidade, relações autônomas, inovadoras e socialmente inclusivas de modo a valorizar e otimizar o uso dos espaços públicos na produção da saúde, transcendendo a prevenção de doenças (Carvalho, 2006). É necessário destacar que o indivíduo mobiliza "junto com um corpo de ossos e músculos, um corpo de afetos e de expansão da experiência humana" (Ceccim e Bilibio, 2007, p. 54).

É muito apropriado pensar as políticas de formação em educação física e saúde coletiva tomando como eixo central o conceito de prática corporal, pois ele está muito mais alinhado à humanização do cuidado e à atenção integral à saúde do que à noção de atividade física. Mas, apesar do potencial de resposta das práticas corporais às demandas do SUS, ainda prevalece no âmbito da formação e das pesquisas a retórica da atividade física. Durante a graduação, são poucas as oportunidades de 'experimentos' com as práticas corporais no contexto do serviço público de saúde. O PET-Saúde é uma das poucas estratégias de aproximação dos acadêmicos aos serviços que tem conseguido acolher outros modos de pensar e fazer o cuidado com as práticas corporais.

Há duas experiências recentes de sistematização das aprendizagens desenvolvidas por alunos e alunas do PET-Saúde (USP e UFRGS) divulgadas em diferentes contextos: o trabalho intitulado "As Práticas Corporais no SUS: o PET-Saúde 'observando' o direito ao cuidado e à atenção em saúde", apresentado por Andrea Vidal e Yara Maria de Carvalho (2011) no V Congresso Nacional de Educação Física, na cidade de Bauru, e o Trabalho de Conclusão de Curso (TCC) de Guilherme dos Santos Torres (2011), intitulado "Educação Física na Estratégia de Saúde da Família: relato de experiência sobre as atividades na Unidade de Saúde da Família Rincão". Uma pequena amostra do que se pode alcançar em termos de ensino na saúde com o enraizamento do PET-Saúde nas IES.

Considerando a magnitude e a complexidade dessa estratégia voltada para estimular a aproximação entre professores e pesquisadores, univer- 
sitários, profissionais da saúde e comunidade, no âmbito da atenção primária à saúde, investindo em metodologias transformadoras, baseada em problemas, partindo de eixos temáticos, trazendo os 'casos' para as rodas de conversa e definindo as ações a partir das necessidades dos usuários, reiteramos que é fundamental nos envolvermos com o PET-Saúde. Estamos convictos de que, para pensar e reinventar a formação em educação física, especialmente no que se refere às competências e habilidades necessárias para o trabalho em equipe, multiprofissional e intersetorial sintonizado com os princípios do SUS, será necessária a intervenção comprometida com o serviço e, sobretudo, com os usuários. É também por essas razões que o PET-Saúde é o ponto de convergência deste coletivo de pesquisadores.

\section{Considerações finais}

Em que pese ainda a tímida inserção de estudantes e profissionais da educação física no SUS, se comparada às profissões 'irmãs' da área da saúde, já se observa interesse de parte dos pesquisadores e grupos de estudo e pesquisa, isoladamente, em participar dos debates no campo da saúde coletiva com o intuito de qualificar a inserção nesses espaços, a formação fundamentada na saúde coletiva e a intervenção orientada pelos princípios do SUS. Nesse sentido, as experiências acadêmicas no Pró-Saúde e no PET-Saúde e a atuação profissional na ESF e no Nasf podem ser interessantes para reorientar as ações em saúde.

Atualmente, estamos buscando operacionalizar os conceitos que fundamentam nossas investigações, no âmbito da graduação e da pós-graduação, voltados à atenção primária e à inclusão das práticas corporais no rol de tecnologias leves 11 à disposição dos usuários do SUS. Temos contado com o aporte do Ministério da Saúde e do Ministério da Educação que, por meio de portarias e editais de financiamento de pesquisa, estão investindo em políticas intersetoriais e interdisciplinares para qualificar a atenção e o cuidado em saúde.

Investigar e avaliar programas, projetos e serviços que se propõem a atuar na consolidação de políticas de formação mais abrangentes, potencializando os espaços de inserção das práticas corporais com vistas à promoção da saúde, ou seja, com um enfoque mais participativo e democrático, poderá resultar na ressignificação das competências e habilidades dos profissionais da saúde.

Nessa direção, nosso desafio demarca como ponto de partida investigativo o PET-Saúde, que se destaca como uma importante estratégia de reorientação da formação em saúde, de modo geral. É assim, pensando e intervindo sobre as propostas e as práticas - como vimos trilhando -, que 
pretendemos alimentar as políticas públicas e sociais e, ao mesmo tempo, chamar a atenção da educação física para a dimensão e a complexidade que implica a produção de saúde em defesa da vida.

\section{Colaboradores}

Os autores trabalharam em conjunto em todas as etapas de produção do manuscrito.

\section{Notas}

1 Professor da Escola de Educação Física da Universidade Federal do Rio Grande do Sul (UFRGS), Porto Alegre, Rio Grande do Sul, Brasil. Doutor em Educação Física pela Universidade Federal do Rio Grande do Sul (UFRGS). < brancofraga@gmail.com>

Correspondência: Rua Felizardo, 750, Jardim Botânico, CEP 90690-200, Porto Alegre, Rio Grande do Sul, Brasil.

2 Professora do Departamento de Pedagogia do Movimento do Corpo Humano da Universidade de São Paulo (USP), São Paulo, São Paulo, Brasil. Doutora em Saúde Coletiva pela Universidade Estadual de Campinas (Unicamp). <yaramc@usp.br>

3 Professor do Centro de Educação Física e Desportos da Universidade Federal do Espírito Santo (Ufes), Vitória, Espírito Santo, Brasil. Doutor em Ciências Humanas pela Universidade Federal de Santa Catarina (UFSC). <ivanmgomes@hotmail.com>

4 Que são as seguintes: “(a) gestão do ensino na saúde; (b) currículo e processo ensinoaprendizagem na graduação e pós-graduação em saúde; (c) avaliação no Ensino na Saúde; (d) formação e desenvolvimento docente na saúde; (e) integração universidades e serviços de saúde; (f) políticas de integração entre saúde, educação, ciência e tecnologia; (g) tecnologias presenciais e a distância no Ensino na Saúde" (Brasil, 2010, p. 2).

5 O livro Nas fronteiras da Educação Física e das Ciências Humanas: itinerários (Carvalho, 2009) dá pistas a respeito desse processo de formação e articulação entre diferentes áreas no campo da educação física no Brasil.

6 Em 2006, a editora Autores Associados publicou a tese em livro com título homônimo (Fraga, 2006). 
7 Apesar da diversidade de propostas que surgiu em torno do Movimento Renovador da Educação Física, destacamos nesse processo uma repedagogização da teorização em educação física (Betti, 2005). Nesse ínterim, “a entrada mais decisiva das ciências sociais e humanas na área da $\mathrm{EF}$, processo que tem vários determinantes, permitiu ou fez surgir uma análise crítica do paradigma da aptidão física. Mas esse viés encontra-se num movimento mais amplo que tem sido chamado de movimento renovador da EF brasileira na década de 1980" (Bracht, 1999, p. 77).

8 Trabalhos nessa direção têm sido efetuados por meio, primeiramente, da inserção e, posteriormente, da relação construída com o grupo de pesquisa Núcleo de Estudos e Pesquisa em Subjetividade e Políticas (Nepesp/Ufes/CNPq). Tais trabalhos resultaram na dissertação defendida por Almeida (2008).

9 O Promed foi um programa que incentivou e manteve processos de transformação em 19 escolas médicas brasileiras.

10 É interessante observar que, em 1998, o CNS homologa a resolução CNS n. 287, que não mais reconhece como profissionais da saúde de nível superior as categorias listadas na resolução n. 218/1997, e sim relaciona as categorias profissionais de saúde de nível superior para fins de atuação do Conselho Nacional de Saúde.

11 Na teorização de Emerson Merhy (1997), são as tecnologias de caráter imaterial relacionadas à interação humana no processo de trabalho em saúde. São as tecnologias de relações, de produção de comunicação, de acolhimento, de vínculos, de autonomização e responsabilização presentes no trabalho vivo.

\section{Referências}

ALMEIDA, Ueberson Ribeiro. Nas trilhas da atividade docente: análise da relação saúdetrabalho de professores de educação física no cotidiano escolar, 2008. Dissertação (Mestrado em Educação Física) - Centro de Educação Física e Desportos, Universidade Federal do Espírito Santo, Vitória, 2008.

AZEVEDO, Ângela Celeste Barreto de; MALINA, André. Memória do currículo de formação profissional em educação física no Brasil. Revista Brasileira de Ciências do Esporte, Campinas, n. 2, v. 25, p. 129-142, jan. 2004.

AYRES, José Ricardo de C. Mesquita. et al. Caminhos da integralidade: atenção à saúde de adolescentes e jovens na atenção primária à saúde. Interface - Comunicação, Saúde, Educação, Botucatu, n. 40, v. 16, p. 67-82, abr. 2012.
BECCALLI, Michel. Mais que atividade física: os usos e entendimentos da saúde entre usuários do Serviço de Orientação ao Exercício da Prefeitura Municipal de Vitória, 2012. Dissertação (Mestrado em Educação Física) - Centro de Educação Física e Desportos, Universidade Federal do Espírito Santo, Vitória, 2012.

BENITES, Larissa Cerignoni; SOUZA NETO, Samuel de; HUNGER, Dagmar. O processo de constituição histórica das diretrizes curriculares na formação de professores de educação física. Educação e Pesquisa, São Paulo, n. 2, v. 34, p. 343-360, maio-ago. 2008.

BETTI, Mauro. Educação física. In: GONZÁLEZ, Fernando Jaime; FENSTERSEIFER, Paulo (Orgs.). Dicionário crítico de educação física. Ijuí: Unijuí, 2005. p. 144-150. 
BRACHT, Valter. A constituição das teorias pedagógicas da educação física. Caderno Cedes, Campinas, ano XIX, n. 48, p. 69-88, ago. 1999.

BRACHT, Valter. et al. Pesquisa em ação: educação física na escola. 3. ed. Ijuí: Unijuí, 2007.

BRASIL. Conselho Federal de Educação. Resolução n. 03/1987, de 16 de junho de 1987. Fixa os mínimos de conteúdo e duração a serem observados nos cursos de graduação em educação física (bacharelado e/ou licenciatura plena). Brasília, DF, 1987. Disponível em: <www.ufpb.br/sods/consepe/resolu/ 1990/Res0387-cfe.htm>. Acesso em: 16 set. 2010.

. Conselho Nacional de Educação. Conselho Pleno. Resolução CNE/CP n. 1/2002, de 18 de fevereiro de 2002. Institui diretrizes curriculares nacionais para a formação de professores da educação básica, em nível superior, curso de licenciatura, de graduação plena. Brasília, DF, 2002a. Disponível em: <http://portal.mec.gov.br/cne/arquivos/ pdf/CP012002.pdf $>$. Acesso em: 24 nov. 2010.

Conselho Nacional de Educação. Resolução CNE/CP n. 2/2002, de 19 de fevereiro de 2002. Institui a duração e a carga horária dos cursos de licenciatura, de graduação plena, de formação de professores da educação básica em nível superior. Brasília, DF, 2002b. Disponível em: <http://portal.mec.gov.br/cne/arquivos/ pdf/CP022002.pdf $>$. Acesso em: 24 nov. 2010 .

Conselho Nacional de Educação. Câmara de Educação Superior. Resolução n. 7/2004, de 31 de março de 2004. Institui as diretrizes curriculares para os cursos de graduação em educação física. Brasília, DF, 2004. Disponível em: <http://portal.mec. gov.br/index.php?option $=$ com_content \& view $=$ article $\& i d=12991>$. Acesso em: 18 dez. 2010.

Portaria interministerial n. 3.018, de 26 de novembro de 2007. Diário Oficial da República Federativa do Brasil, Brasília, DF, seção I, p. 44, 27 nov. 2007. Disponível em: $<$ www.prosaude.org/leg/portaria_prosaude nov_2007_DOU.pdf $>$. Acesso em: 17 jun. 2010 .

Ministério da Saúde. Secretaria de Gestão do Trabalho e da Educação na Saúde. Programa Nacional de Reorientação da Formação Profissional em Saúde (Pró-Saúde). Brasília, DF: Ministério da Saúde. 2009. Disponível em: <http://prosaude.org/not/ prosaude-maio2009/proSaude.pdf $>$. Acesso em: 17 jun. 2010.

Coordenação de Aperfeiçoamento de Pessoal de Nível Superior (Capes). Diretoria de Programas e Bolsas no País (DPB). Coordenação-Geral de Programas Estratégicos (CGPE). Coordenação de Indução e Inovação (CII). Pró-ensino na saúde: edital n. 024/2010. Brasília, DF: Capes, 2010.

Ministério da Saúde. Portal da saúde: saiba mais sobre o PET-Saúde. Brasília, DF: Ministério da Saúde, 2011. Disponível em: <http://portal.saude.gov.br/portal/saude/ profissional/visualizar_texto.cfm?idtxt= 32571>. Acesso em: 27 jun. 2011.

CARVALHO, Yara Maria de. A arte de fazer a vida melhor: narrativas dos que fazem a festa de Achiropita. Tese (Doutorado em Saúde Pública - Faculdade de Ciências Médicas, Universidade Estadual de Campinas, Campinas, 1999.

O 'mito' da atividade física e saúde. 4. ed. São Paulo: Hucitec, 2004.

Promoção da saúde, práticas corporais e atenção básica. Revista Brasileira de Saúde da Família, Brasília, v. VII, p. $33-$ 45, 2006.

Nas fronteiras da educação física e das ciências humanas: itinerários. São Paulo: Hucitec, 2009.

As práticas corporais na atenção primária em saúde: avaliando os cuidados com o corpo nas UBS do distrito Butantã em São Paulo. In: SEMINÁRIO DE AVALIA- 
ÇÃO/PROGRAMA DE PESQUISA PARA O SUS - PPSUS/SP, 2010, São Paulo. Anais... p. 5-6.

CASPERSEN, Carl J.; POWELL, Kenneth E.; CHRISTENSON, Gregory M. Physical Activity, Exercise, and Physical Fitness: Definitions and Distinctions for Health-related Research. Public Health Reports, v. 100, n. 2, p. 127-131, 1985.

CECCIM, Ricardo B.; BILIBIO, Luiz Fernando. Singularidades da educação física na saúde: desafios à educação de seus profissionais e ao matriciamento interprofissional. In: FRAGA, Alex Branco; WACHS, Felipe. (Orgs.). Educação física \& saúde coletiva: políticas de formação e perspectivas de intervenção. Porto Alegre: Editora da UFRGS, 2007. p. 47-62.

FIGUEIREDO, Zenólia Christina Campos. (Org.). Formação profissional em educação física e mundo do trabalho. 1. ed. Vitória: Faculdade Salesiana de Vitória, 2005.

FRAGA, Alex B. Exercício da informação: governo dos corpos no mercado da vida ativa. Campinas: Autores Associados, 2006.

FRAGA, Alex B. et al. Alterações curriculares de uma escola septuagenária: um estudo sobre as grades dos cursos de formação superior em educação física da ESEF/UFRGS. Movimento, n. esp., v. 16, p. 61-95, 2010.

FRAGA, Alex B.; WACHS, Felipe. (Orgs.). Educação física \& saúde coletiva: políticas de formação e perspectivas de intervenção. Porto Alegre: Editora da UFRGS, 2007.

FRAGA, Alex B. et al. (Orgs.). Políticas de lazer e saúde em espaços urbanos. Porto Alegre: Gênese, 2009.

FREITAS, Fabiana Fernandes de; BRASIL, Fernanda Kundrát; SILVA, Cinthia Lopes da. Práticas corporais e saúde: novos olhares. Revista Brasileira de Ciências do Esporte, Campinas, n. 3, v. 27, p. 169-183, 2006.

A educação física no serviço público de saúde. São Paulo: Hucitec, 2007.
GOMES, Ivan Marcelo. Conselheiros modernos: propostas para a educação do indivíduo saudável, 2008. Tese (Doutorado Interdisciplinar em Ciências Humanas) - Programa de Pós-Graduação Interdisciplinar em Ciências Humanas, Universidade Federal de Santa Catarina, Florianópolis, 2008.

HADDAD, Ana Estela et al. Programa de Educação pelo Trabalho para a Saúde PET-Saúde. Cadernos ABEM, Rio de Janeiro, v. 5, p. 6-12, out. 2009.

LAZAROTTI FILHO, Ari et al. O termo práticas corporais na literatura científica brasileira e sua repercussão no campo da educação física. Movimento, Porto Alegre, v. 16, n. 1, p. 11-29, jan.-mar. 2010.

MARCONDES, Rosana. As práticas corporais no serviço público de saúde: uma aproximação entre educação física e saúde coletiva, 2007. Dissertação (Mestrado em Educação Física) - Escola de Educação Física e Esporte, Universidade de São Paulo, São Paulo, 2007.

MERHY, Emerson. Em busca do tempo perdido: a micropolítica do trabalho vivo em saúde. In: MERHY, Emerson; ONOCKO, Rosana (Orgs.). Agir em saúde: um desafio para o público. São Paulo: Hucitec, 1997. p. 71-112.

MOLINA NETO, Vicente; MOLINA, Rosane M. K. Identidade e perspectivas da educação física na América do Sul: formação profissional em educação física no Brasil. In: BRACHT, Valter; CRISORIO, Ricardo. (Orgs.). A educação física no Brasil e na Argentina: identidade, desafios e perspectivas. 1. ed. Campinas: Autores Associados, 2003. p. 259-278.

PASQUIM, Heitor Martins. A Saúde Coletiva nos cursos de graduação em Educação Física. Saúde e Sociedade, São Paulo, n. 1, v. 19, p. 193-200, 2010.

TERRA, Dinah Vasconcellos; SOUZA JÚNIOR, Marcílio (Orgs.). Formação em educação física \& ciências do esporte: políticas e cotidiano. São Paulo: Hucitec/Colégio Brasileiro de Ciência do Esporte, 2010. 
TORRES, Guilherme dos Santos. Educação física na estratégia de saúde da família: relato de experiência sobre as atividades na Unidade de Saúde da Família Rincão. 2011. Lume (repositório digital da Universidade Federal do Rio Grande do Sul). Disponível em: <http:/hdl.handle.net/10183/32278>. Acesso em: 17 out. 2011.

VIDAL, Andrea; CARVALHO, Yara Maria. As práticas corporais no SUS: o PET-Saúde 'observando' o direito ao cuidado e à atenção em saúde. In: CONGRESSO NACIONAL DE EDUCAÇÃO FÍSICA; REUNIÃO CIENTÍFICA “REUNINDO EXPERIÊNCIAS E PRODUZINDO SABERES NA EDUCAÇÃO FÍSICA", 16., 2011, São Bernardo do Campo, 2011, Anais... São Bernardo do Campo: Associação Paulista de Saúde Pública, 2011.
WACHS, Felipe. Educação física e saúde mental: uma prática de cuidado emergente em Centros de Atenção Psicossocial (CAPS), 2008. Lume (repositório digital da Universidade Federal do Rio Grande do Sul). Disponível em: <http:/hdl.handle.net/10183/ 14069>. Acesso em: 17 out. 2011.

WARSCHAUER, Marcos et al. As escolhas das práticas corporais e dos profissionais que as conduzem nas unidades básicas de saúde do distrito Butantã-SP. In: CONGRESSO BRASILEIRO DE CIÊNCIAS DO ESPORTE, 15.; CONGRESSO INTERNACIONAL DE CIÊNCIAS DO ESPORTE, 2., 2007, Recife. Anais... Recife, 2007.

Recebido em 09/12/2011

Aprovado em 19/04/2012 